\title{
Pengaruh Penjaminan Kredit Daerah Dan Bankable Terhadap Pertumbuhan Umkm Di Provinsi Banten ( Yang Terdaftar Di Pt. Jamkrida Banten Priode 2015-2018)
}

\author{
Deni Sunaryo \\ Universitas Serang Raya, Banten, Indonesia
}

\begin{abstract}
ABSTRAK
Usaha mikro, kecil, dan menengah (UMKM) merupakan salah satu sumber yang dapat diandalkan di Indonesia. Berdasarkan Kementrian Perindustrian Republik Indonesia tahun 2016 sektor UMKM menyumbang 60.34\% terhadap produk domestik bruto (PDB) dalam lima tahun terakhir. Keberadaan UMKM terbukti mampu menjadi penyelamat perekonomian, khususnya di Indonesia. Sektor UMKM menyerap $97.22 \%$ tenaga kerja dari pelaku usaha nasional.

Tujuan penelitian ini adalah untuk menganalisis dan mengetahui pengaruh variabel Penjaminan Kredit Daerah terhadap variabel Pertumbuhan UMKM, pengaruh variabel Bankable terhadap variabel Pertumbuhan UMKM, dan pengaruh variabel Penjaminan Kredit Daerah dan Bankable terhadap variabel Pertumbuhan UMKM. Metode pengumpulan data sekunder melalui PT Jamkrida Banten dengan cara bertatap muka langsung dengan jumlah 80 perusahaan/pelaku UMKM Priode 20152018. Data dianalisis menggunakan analisis deskriptif dan regresi linear berganda. Hasil penelitian ini menunjukkan secara parsial variabel Penjaminan Kredit Daerah berpengaruh signifikan terhadap variabel Pertumbuhan UMKM dengan arah negatif, variabel Bankable Kredit UMKM berpengaruh signifikan terhadap variabel Pertumbuhan UMKM dengan arah positif. Secara simultan variabel Penjaminan Kredit Daerah dan variabel Bankable berpengaruh signifikan terhadap variabel Pertumbuhan UMKM. Hasil penelitian ini dapat mengkonfirmasi temuan sebelumnya dan diharapkan dapat memberikan kontribusi bagi penelitian selanjutnya.
\end{abstract}

Kata kunci: Penjaminan Kredit Daerah, Bankable, dan Pertumbuhan UMKM (Market Value Ratio) 


\begin{abstract}
Micro, small and medium enterprises (UMKM) are one of the most reliable sources in Indonesia. Based on the Ministry of Industry of the Republic of Indonesia in 2016 the UMKM sector contributed $60.34 \%$ of gross domestic product (GDP) in the last five years. The existence of MSMEs has proven to be able to save the economy, especially in Indonesia. The UMKM sector absorbs $97.22 \%$ of the workforce from national businesses. The purpose of this study was to analyze and determine the influence of the Regional Credit Guarantee variable on the UMKM Growth variable, the influence of the Bankable variable on the UMKM Growth variable, and the influence of the Regional and Bankable Credit Guarantee variable on the UMKM Growth variable. Secondary data collection methods through PT Jamkrida Banten by way of face to face with the number of 80 companies / perpetrators of the 2015-2018 UMKM period. Data were analyzed using descriptive analysis and multiple linear regression. The results of this study indicate that partially the Regional Credit Guarantee variable significantly influences the MSME Growth variable in a negative direction, the Bankable Credit UMKM variable has a significant effect on the UMKM Growth variable in a positive direction. Simultaneously the Regional Credit Guarantee variable and the Bankable variable significantly influence the UMKM Growth variable. The results of this study can confirm previous findings and are expected to contribute to further research.
\end{abstract}

Keywords: Regional Credit Guarantee, Bankable, and Growth UMKM (Market Value Ratio) 
PRIMANOMICS : JURNAL EKONOMI DAN BISNIS - VOL. 17. NO. 3 (2019)

Versi Online Tersedia di : https://jurnal.ubd.ac.id/index.php/ds

| 1412-632X (Cetak) | 2614-6789 (Online) |

\section{PENDAHULUAN}

Menurut pendapat (Kasmir, 2004; 26), bahwa; dana yang masyarakat yang diditipkan ke Bank akan sangat membantu bank dalam melaksanakan kegiatan penyaluran kembali kepada nasabah-nasabah terutama untuk kegiatan produktif seperti pada sektor riil atau sekarang dikenal dengan UMKM. Peranan Bank sebagai lembaga keuangan tidak pernah terlepas dari masalah kredit, bahkan pemberian kredit merupakan kegiatan utamanya. Besarnya jumlah kredit yang disalurkan akan menentukan keuntungan bank. Jika bank tidak mampu menyalurkan kredit, sementara dana yang terhimpun dari simpanan sudah banyak, maka menyebabkan bank tersebut rugi.

Pengelolaan kredit yang dilakukan oleh bank harus dilakukan dengan sebaik-baiknya mulai dari perencanaan, penganggaran, jumlah kredit, penentuaan suku bunga, prosedur pemberian kredit, analisis pemberian kredit sampai kepada pengendalian kredit yang macet (Sugiono,Arief 2009; 120). Disisi lain dalam rangka meningkatkan pendapatan perkapita masyarakat, pemerintah/ pemerintah daerah perlu membuat kebijakan yang relevan terhadap lembaga keuangan tersebut agar masyarakat (nasabah) berperan aktif dalam memanfaatkan lembaga tersebutDari sekian banyak kasus masih ada ketidak sadaran sebagian masyarakat (nasabah) yang melalaikan kewajibannya dalam membayar angsuran kepada pihak kreditur, ini sangat merugikan pihak perbankan atau lembaga penjamin/ perusahaan BUMN/ BUMD. Biasanya beberapa hal yang menjadi kendala dalam proses kredit antara lain; 1) kemungkinan terjadinya kredit macet yang disebabkan kelalaian nasabah UMKM dalam membayar angsuran kepada penerima jaminan; 2) Kelambatan penyelesaian administrasi; 3) Nasabah UMKM yang tidak konsisten dalam menjalankan kerjasamanya dan menganggap pihak penjamin dan penerima jaminan akan menyelesaikan masalah dengan mudah jika terjadi kelalaian.

Menurut data yang disampaikan oleh Kementrian Koperasi dan UMKM dalam Perkembangan Data Usaha Mikro, Kecil, dan Menengah (UMKM) serta Usaha Besar (UB) seperti yang terdapat dalam www.depkop.go.id, nomor 1 (2012): 2011-12, hingga tahun 2013, proporsi sektor usaha yang masuk dalam kategori UMKM pada total unit usaha yang terdaftar cukup besar. Jumlah UMKM tercatat sebesar 57.895.721 sementara unit usaha yang masuk dalam kategori unit usaha besar hanya sebanyak 5.066 unit usaha. Demikian juga dengan kemampuan untuk menampung jumlah tenaga kerja. Unit usaha besar mempekerjakan pegawai sebesar 3.537.162 tenaga kerja, sementara tenaga kerja yang bekerja untuk sektor UMKM mencapai 114.144.082. Data tersebut menunjukkan dari total tenaga kerja yang ada di Indonesia, 97\% diantaranya bekerja untuk sektor UMKM. Sedangkan jika melihat dari komposisi terhadap PDB harga berlaku, sektor UMKM menyumbang sebesar 60,34\% sisanya yaitu sebesar 39,66\% merupakan sumbangsih dari sektor usaha besar. Jika melihat dari sisi ekspor non migas yang dilakukan oleh UMKM, maka proporsi mereka sebesar 15,68\% dan sebanyak $85,94 \%$ ekspor non migas dilakukan oleh usaha besar. 
Dengan melihat peluang dan kontribusi serta kenyataan yang ada peran UMKM terhadap perekonomian, maka maka dipandang perlu adanya grand strategy pengembangan melalui pemberdayaan UMKM yang menjadi sumber pertumbuhan baru perekonomian Indonesia, dalam hal dapat berperan dalam : (1). Mensejahterakan masyarakat, (2). Membuka lapangan pekerjaan, (3). Wahana pemerataan pembangunan untuk mengatasi kesenjangan pendapatan antar masyarakat, antar wilayah serta antara pedesaan dan perkotaan yang mempu mengurangi arus urbanisasi, (4). Pasar input dan output hasil-hasil produk UMKM, (5). Penghasil devisa, (6). Peningkatan pendapatan nasional (Renstra Kemenkop RI: 2012) dengan demikian terlihat jelas adanya kontribusi nyata sektor Usaha Mikro, Kecil dan Menengah (UMKM) terhadap produk domestik Regional bruto (PDRB) khususnya di Propinsi Banten, paling tidak dalam kurun waktu lima tahun terakhir sangat terasa.

Badan Pusat Statistik Propinsi Banten mencatat adanya peninkatan kontribusi sektor UMKM dari 57,84 persen menjadi 60,34 persen. Tak hanya itu, sektor UMKM juga telah membantu penyerapan tenaga kerja. Serapan tenaga kerja pada sektor UMKM tumbuh dari 96,99 persen menjadi 97,22 persen dalam periode lima tahun terakhir. Sehingga berdampak pada pertumbuhan ekonomi di provinsi Banten yang terus mengalami peningkatan dilihat dari perkembangan Produk Domestik Regional Bruto (PDRB) nominal.

Data peningkatan PDRB Provinsi Banten dari tahun ke tahun terus meningkat dalam kurun waktu 2013-2016, secara nominal PDRB Provinsi Banten bertambah 138.490 miliar rupiah, dari 377.836 miliar pada tahun 2013 menjadi 516.326 miliar rupiah pada tahun 2016 atau meningkat sebesar 73\%. Hal tersebut dapat menunjukkan bagaimana peran UMKM sangat dominan dalam pertumbuhan ekonomi Indonesia. Sehingga pemberdayaan UMKM merupakan sesuatu yang sangat penting dalam upaya meningkatkan pertumbuhan perekonomian di Indonesia. Sumbangsih UMKM terhadap PDB menjadikan indikator pentingnya UMKM dalam peningkatan pertumbuhan perekonomian di Indonesia, Produk Domestik Bruto (PDB) merupakan indikator pertumbuhan perekonomian, dimana pertumbuhan ekonomi adalah proses kenaikan output perkapita dalam jangka yang panjang.

Berdasarkan data Badan Pusat Statistik (BPS) pada tahun 2016, UMKM menyumbangkan 57,65\% dari perekonomian Banten (PDRB). Angka tersebut merupakan yang terbesar diantara bidang usaha lain. Berdasarkan data Kementerian Koperasi dan UKM (2017), di Provinsi Banten terdapat 1,07 juta UMKM (20\% dari angkatan kerja) Angka tersebut sangat besar mengingat jumlah angkatan kerja di Banten sebesar 5,6 juta. Tidak semua pelaku usaha dapat menyedia-kan modal secara menyeluruh. sehingga diperlukan peminjaman pada bank dalam bentuk kredit. Dalam melakukan peminjaman, bank membutuhkan jaminan dari pelaku usaha UMKM. Pihak bank memerlukan jaminan berupa harta kekayaan debitur untuk dijadikan jaminan apabila debitur tidak memenuhinya dalam melunasi kredit yang diajukan tersebut. Namun tidak semua pihak debitur dapat menyediakan jaminan yang sesuai dengan nominal peminjaman yang dilakukan, sehingga debitur membutuhkan bantuan dari perusahaan penjaminan sebagai pihak ketiga untuk membantu memberikan jaminan. 
PRIMANOMICS : JURNAL EKONOMI DAN BISNIS - VOL. 17. NO. 3 (2019)

Versi Online Tersedia di : https://jurnal.ubd.ac.id/index.php/ds

| 1412-632X (Cetak) | 2614-6789 (Online) |

Oleh karenanya diharapkan pemerintah mendirikan insfrastruktur pendukung berupa perusahaan penjaminan kredit guna memayungi keberadaan para pengusaha UMKM yang jumlahnya sangat banyak. Dengan demikian, bank sangat berperan sebagai penggerak roda perekonomian supaya pertumbuhan ekonomi suatu negara dapat berjalan baik.

Menurut Sukirno (2011:429) faktor-faktor penting yang mempengaruhi pertumbuhan ekonomi adalah tanah dan kekayaan alam. Jumlah dan mutu dari penduduk dan tenaga kerja, barang-barang modal dan tingkat teknologi, sistem sosial sistem sosial, serta sikap masyarakat luas pasar sebagai sumber pertumbuhan. Berdasarkan pernyataan tersebut maka dapat dikatakan bahwa tanah dan kekayaan alam lainya mempunyai pengaruh yang penting terhadap pertumbuhan ekonomi. Karena dengan keberadaan tanah dan kekayaan alam dapat meningkatkan pendapatan mereka. Selain itu dikatakan pula bahwa jumlah dan mutu tenaga kerja juga berpengaruh. Seseorang yang memiliki kualitas sumberdaya yang baik dapat meningkatkan produktifitas kerjanya, sehingga berpengaruh terhadap pendapatanya.

Menurut Dinas Koperasi dan UMKM Banten (2017), terdapat 984.188 pelaku usaha UKM. Rinciannya 823.496 pelaku usaha mikro, 153.313 unit usaha kecil dan 7.309 pelaku usaha UKM tingkat menengah. Sedangkan koperasi yang aktif sendiri berjumlah 4.658 unit. Perlu adanya sinkronisasi antara kebijakan pemerintah dan pemerintah daerah disatu pihak dengan implementasi kebijakan yang ditempuh dalam mengarahkan peran serta masyarakat dalam pemberdayaan UMKM demi meningkatkan kinerja dan kompetensi dan usahanya (Dinas Koperasi dan UKM Provinsi Banten, 2014).

Menurut Bank Indonesia Banten (2017) Bankable perbankan ke usaha kecil di Provinsi Banten pada kuartal I/2016 melonjak 50,17\% menjadi Rp 8,77 triliun dibandingkan periode yang sama tahun 2015. Jika dibandingkan dengan kuartal I/2015, pertumbuhan kredit usaha kecil hanya mencatatkan pertumbuhan 10,34\% dari kuartal I/2014. Berdasarkan data Indikator Banten (2016) yang dirilis dari Bank Indonesia, komposisi kredit UMKM mayoritas disalurkan ke usaha menengah dengan nilai Rp 18,25 triliun, disusul oleh kredit ke usaha kecil Rp 8,77 triliun, dan kredit ke usaha mikro Rp3,61 triliun pada periode yang sama. Jika dirinci, hanya pertumbuhan kredit usaha menengah yang mengalami perlambatan 4,28\%. Padahal, pada kuartal I/2015, pertumbuhan kredit usaha menengah mencapai 15,74\%. Kendati melambat, porsi kredit ke usaha menengah masih mendominasi mencapai 59,48\% dari total kredit UMKM yang disalurkan sepanjang Januari-Maret 2016. Pada saat yang sama, pangsa kredit UMKM di Banten mencatatkan tren kenaikan sebesar 12,95\% pada kuartal I/2016 dari total pinjaman perbankan senilai Rp236,83 triliun. Pada kuartal I/2015, pangsa pasar kredit UMKM mencapai 12,7\%. Sementara itu, Pemerintah Provinsi Banten terus berupaya untuk meningkatkan kerjasama kemitraan dengan sejumlah pusat perbelanjaan sehingga mampu meningkatkan pangsa pasar dan daya saing UMKM. 
Berdasarkan data Dinas Koperasi dan UMKM Banten, jumlah UMKM sebanyak 984.118 unit usaha dan 6.227 unit koperasi (Tempo, 2016).

Memperoleh laba merupakan tujuan utama berdirinya suatu lembaga keuangan baik bank ataupun lembaga keuangan yang lainnya. Laba yang diperoleh tidak saja digunakan untuk membiayai operasi perusahaan, tetapi juga digunakan untuk ekspansi dimasa yang akan datang. Kemudian yang lebih penting lagi apabila suatu lembaga keuangan terus-menerus memperoleh laba, maka ini berarti kelangsungan hidup badan usaha tersebut akan terjamin. Karena aktifitas terbesar bank adalah pada bidang perkreditan, maka dari aktifitas ini akan menentukan besarnya laba yang akan diperoleh dalam suatu periode.

Bankable UMKM mempunyai pengaruh terhadap jumlah pendapatan operasional bank, pernyataan tersebut diperkuat oleh Lukman Dendawijaya (2005: 23) yang menyatakan "Pendapatan operasional terbesar bank diperoleh dari pendapatan bunga, provisi, komisi serta pendapatan lainnya yang diterima sebagai akibat dari Bankable bank." Pernyataan tersebut juga diperkuat oleh Kasmir (2003: 37) yang menyatakan "Bankable menghasilkan bunga pinjaman yang merupakan komponen utama faktor pendapatan operasional bank." Dari kedua pernyataan tersebut dapat ditarik kesimpulan bahwa Bankable UMKM mempunyai pengaruh terhadap jumlah pendapatan operasional, karena apabila Bankable UMKM meningkat, maka akan diikuti peningkatan pendapatan operasional yang diterima bank.

Setiap bank pasti berusaha untuk terus meningkatkan perolehan labanya, karena kegiatan terbesar bank adalah pada bidang penyaluran kredit, maka Bankable mempunyai pengaruh langsung terhadap laba operasional yang diperoleh bank selama suatu periode. Bankable menghasilkan pendapatan operasional berupa pendapatan bunga, provisi, komisi dan lain lain, selain itu Bankable juga mempunyai risiko terjadinya kredit bermasalah yang merupakan komponen beban bagi bank, karena bank berpotensi tidak akan mendapatkan pendapatan bunga dan sejumlah pokok kredit yang telah disalurkan. Pernyataan diatas diperkuat oleh Kasmir (2005: 71) yang menyatakan "Peranan perbankan sebagai lembaga keuangan tidak terlepas dari masalah kredit, bahkan kegiatan bank sebagai lembaga keuangan, pemberian kredit merupakan kegiatan utamanya, besarnya jumlah kredit yang disalurkan akan menentukan besarnya laba". Teori tersebut diperkuat oleh temuan penelitian Devi Wulandari (2009) yang menyatakan "Bankable mikro utama mempunyai pengaruh tidak signifikan terhadap laba operasional." Dan penelitian yang dilakukan oleh Sri Handayani (2009) yang hasil penelitiannya menyatakan "Bankable mempunyai pengaruh tetapi tidak signifikan terhadap laba operasional". Akan tetapi dari beberapa hasil temuan penelitian juga mengatakan bahwa; Bankable mempunyai pengaruh terhadap laba operasional, karena bila Bankable meningkat, maka diikuti peningkatan laba operasional.

Banyaknya jumlah UMKM akan memberikan efek baik pada pertumbuhan ekonomi karena UMKM adalah satu sektor perekonomian yang potensial dan memberikan banyak manfaat kepada masyarakat, khususnya masyarakat golongan menengah kebawah, salain itu sektor perekonomian potensial UMKM juga mampu memberikan 
sumbangan yang besar dalam pertumbuhan ekonomi, juga mampu meyerap tenaga kerja dalam meningkatkan pendapatan masyarakat.

Berdasarkan latar belakang dan temuan penelitian sebelumnya yang telah diuraikan diatas, serta telah terjadinya fenomena dalam pelaku UMKM, penulis tertarik untuk melakukan penelitian dengan judul "Pengaruh Penjaminan Kredit Daerah dan Bankable UMKM Terhadap Pertumbuhan UMKM di Provinsi Banten Priode 2015$2018^{\prime \prime}$.

\section{Identifikasi Masalah}

Berdasarkan latar belakang yang telah diuraikan di atas, maka faktor faktor penyebab terjadinya masalah masalah dalam penelitian ini dapat diidentifikasi sebagai berikut:

Teridentifikasi sulitnya mendapatkan kredit perbankan untuk kebutuhan modal usaha yang di perlukan bagi UMKM di Banten periode 2015-2018.

Teridentifikasi umumnya pelaku UMKM di Banten periode 2015-2018 tidak memiliki jaminan/ agunan, sehingga akses kredit ke lembaga keuangan terutama perbankan sangat sedikit.

Teridentifikasi umumnya pelaku UMKM di Banten periode 2015-2018 tidak memiliki badan hukum, sehingga akses kredit ke lembaga keuangan terutama perbankan minim. Teridentifikasi dari sisi lembaga keuangan, semakin besar piutang yang dimiliki oleh suatu perusahaan maka semakin besar pula resiko yang dimiliki perusahaan dengan adanya kredit macet.

\section{Rumusan Masalah}

Berdasarkan latar belakang dan temuan penelitian sebelumnya yang telah diuraikan diatas, serta telah terjadinya fenomena pelaku dalam UMKM, maka penulis menetapkan beberapa rumusan masalah sebagai berikut :

Bagaimana pengaruh Penjaminan Kredit Daerah terhadap Pertumbuhan UMKM di Provinsi Banten periode 2015-2018?

Bagaimana pengaruh Bankable UMKM terhadap Pertumbuhan UMKM di Provinsi Banten periode 2015-2018?

Bagaimana pengaruh Penjaminan Kredit Daerah, dan Bankable UMKM secara simultan terhadap Pertumbuhan UMKM di Provinsi Banten?

\section{Tujuan Penelitian}

Berdasarkan latar belakang dan rumusan masalah tersebut diatas, penulis menggaris bawahi dalam tujuan penelitian ini sebagai berikut:

Untuk mengetahui pengaruh Penjaminan Kredit Daerah terhadap Pertumbuhan UMKM di Provinsi Banten periode 2015-2018.

Untuk mengetahui pengaruh Bankable UMKM terhadap Pertumbuhan UMKM di Provinsi Banten periode 2015-2018.

Untuk mengetahui pengaruh Penjaminan Kredit Daerah, dan Bankable UMKM secara simultan terhadap Pertumbuhan UMKM di Provinsi Banten.

\section{Landasan Teori}

Menurut (Sutarno, 2009;142) Jaminan kredit adalah segala sesuatu yang mempunyai nilai mudah untuk diungkan yang diikat dengan janji sebagai jaminan untuk 
pembayaran dari hutang debitur berdasarkan perjanjian kredit yang dibuat kreditur dan debitur.

Penjaminan Kredit Daerah :

$$
\frac{\text { Jaminan Kredit }}{\text { Total Jaminan Kredit }} \times 100 \%
$$

Menurut situs resmi Bankable diambil dari Bahasa Inggris, Bank Ability. Secara harfiah Bankable dapat diartikan sebagai `Nasabah yang memenuhi persyaratan Bank.

$$
\mathrm{NPM}=\frac{\text { Laba Bersih }}{\text { Total Pendapatan }(\text { Sales })}
$$

Menurut Novia Delima Putri, 2014Pertumbuhan UMKM yaitu Peningkatan jumlah perusahaan/pelaku UMKM dalam suatu periode (tahun ke-t) yang terdaftar dan memenuhi syarat perijinan sebagai pelaku UMKM.

$$
\frac{\text { Jumlah UMKM Tahun ke } n-\text { Tahun } t-1}{\text { Jumlah Tahun } t-1}
$$

\section{Kerangka Penelitian}

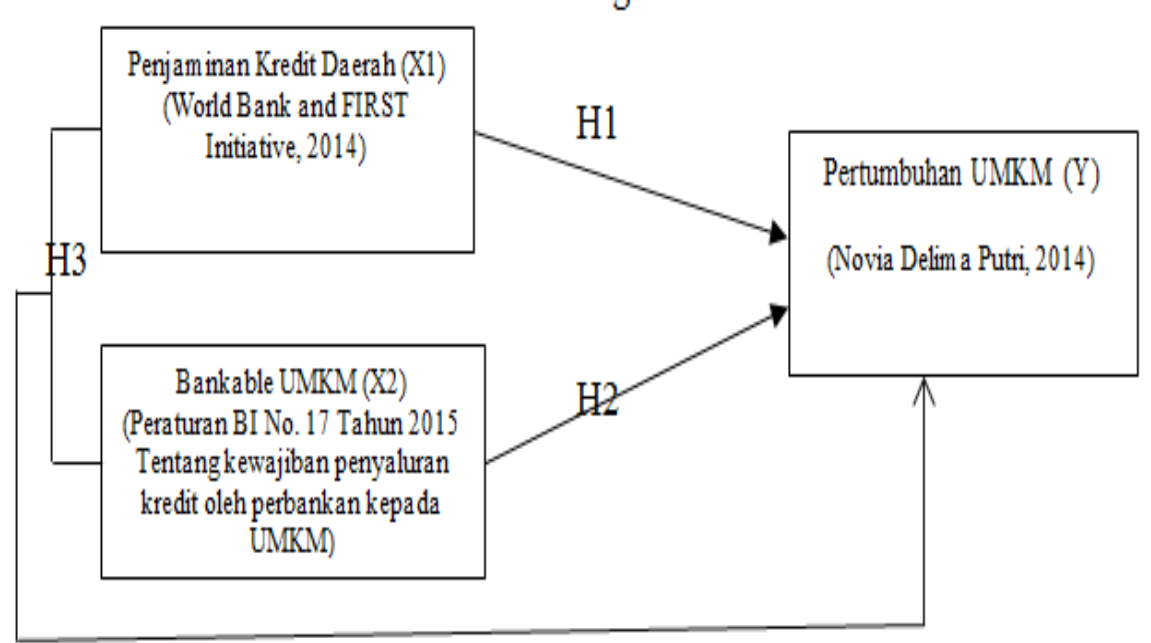

\section{HIPOTESIS}

H1: Penjaminan Kredit Daerah berpengaruh terhadap Pertumbuhan UMKM.

H2: Bankable UMKM berpengaruh terhadap Pertumbuhan UMKM

H3: Penjaminan Kredit Daerah dan Bankable UMKM secara simultan berpengaruh terhadap Pertumbuhan UMKM

\section{METODE PENELITIAN}

Penelitian ini menggunakan metode kuantitatif yang merupakan penelitian eksplanatory reasearch, yaitu penelitian yang bermaksud untuk menguji dan menjelaskan hubungan antar variabel bebas (exogen variable) dan variabel terikat 
PRIMANOMICS : JURNAL EKONOMI DAN BISNIS - VOL. 17. NO. 3 (2019)

Versi Online Tersedia di : https://jurnal.ubd.ac.id/index.php/ds

| 1412-632X (Cetak) | 2614-6789 (Online) |

(endogen variable) (Ruslan, 2006:15). Pemilihan rancangan penelitian pengujian hipotesis (Hyphotheses Testing) ini karena akan menguji secara empirik pengaruh antar variabel penelitian. Penelitian ini menggunakan desain penelitian asosiatif yang merupakan penelitian yang bertujuan untuk mengetahui hubungan antara dua variabel atau lebih. Penentuan jenis penelitian pengujian hipotesis ini dilakukan dengan maksud menjelaskan (confirmatory research) dengan memberikan penjelasan kausal atau hubungan antar variabel yang diteliti melalui pengujian hipotesis.

Rancangan penelitian pengujian hipotesis dalam pengaruh Penjaminan Kredit Daerah dan Bankable UMKM yang diproksi kedalam Kinerja Keuangan yakni; NPM terhadap Pertumbuhan UMKM di Provinsi Banten. Variabel independen dimaksud adalah Penjaminan Kredit Daerah (X1) dan Bankable UMKM (X2) sedangkan Pertumbuhan UMKM di Provinsi Banten adalah variabel dependen (Y), baik secara parsial maupun simultan secara langsung.

\section{HASIL DAN PEMBAHASAN}

Statistik Deskriptif

Tabel 4.1 Tabel Statistik Diskriptif

\begin{tabular}{|l|c|r|r|r|r|}
\multicolumn{7}{|c|}{ Descriptive Statistics } \\
\hline & \multicolumn{1}{|c|}{$\mathrm{N}$} & \multicolumn{1}{c|}{ Mean } & \multicolumn{1}{c|}{ Std. Deviation } & Minimum & Maximum \\
\hline PKD & 320 & .0490 & .04668 & .01 & .56 \\
BKL & 320 & .0938 & .06173 & .04 & .24 \\
GROWT & 320 & 1.0738 & .78337 & .10 & 2.98 \\
H & & & & & \\
\hline
\end{tabular}

Berdasarkan hasil analisis jumlah sample sebesar $n=320$ pengamatan dengan menggunakan statistik deskriptif terdapat nilai variabel Penjaminan Kredit Daerah rata rata tengah (mean) sebesar 0,0490, disusul dengan variabel Bankable sebesar 0,0938, Sedangkan Pertumbuhan UMKM menunjukan nilai rata rata sebesar 1,07738.

\section{Uji Asumsi Klasik}

Uji Normalitas

Gambar 4.3 Grafik Normal Plots Hasil Log Natural (Ln)

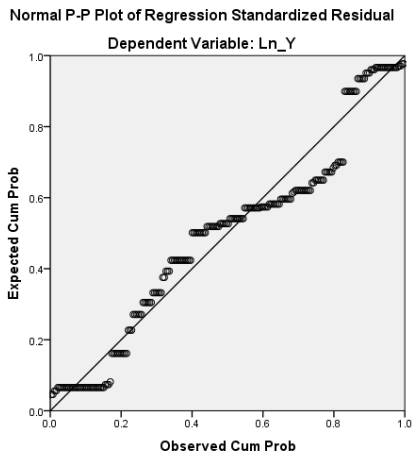


Setelah dilakukan metode atau model regresi yang kami rubah dalam bentuk double-log yaitu pada variabel dependen dan independent menjadi bentuk Logaritma Natural (Ln), maka hasil proses SPSS versi 22 .

\section{Uji Normalitas}

Tabel 4.4 One-Sample Kolmogorov-Smirnov Test

One-Sample Kolmogorov-Smirnov Test

\begin{tabular}{|ll|r|r|r|}
\hline & & PKD & \multicolumn{1}{c|}{ BKL } & GROWTH \\
\hline $\mathrm{N}$ & & 320 & 320 & 320 \\
Normal & Mean & .0490 & .0937 & 1.0738 \\
Parameters $^{\mathrm{a}, \mathrm{b}}$ & Std. & .04668 & .06173 & .78337 \\
& Deviation & .260 & .274 & .321 \\
Most & Absolute & .260 & .274 & .321 \\
Extreme & Positive & -.202 & -.192 & -.196 \\
Differences & Negative & .260 & .274 & .321 \\
Test Statistic & & $.000^{\mathrm{c}}$ & $.000^{\mathrm{c}}$ & $.000^{\mathrm{c}}$ \\
\hline Asymp. Sig. (2-tailed) & &
\end{tabular}
a. Test distribution is Normal.
b. Calculated from data.
c. Lilliefors Significance Correction.

Sumber data : PT. Jamkrida Banten, 2019

Berdasarkan tabel di atas diperoleh nilai statistik Asymp. Sig. (2-tailed) > taraf signifikan (a) 0,05 hasilnya adalah 0,000 < 0,05, adapun nilai Kolmogorov-Smirnov Z untuk variabel Penjaminan Kredit Daerah sebesar 0,260 sedangkan variabel Bankable UMKM sebesar ),274, sehingga dapat disimpulkan bahwa; nilai residual lebih kecil dari 5\% maka uji asumsi klasik normalitas tidak terpenuhi atau tidak berdistribusi normal. Artinya Ho ditolak dan Ha diterima. Sehingga hasil ini menguatkan untuk dilakukan transform data, agar hasil uji grafik histogram maupun grafik normal Plot dan tidak melanggar aturan yang dipersyaratkan.

\section{Uji Multikolinearitas}

Tabel 4.5 Hasil Uji Statistik Coeffisient Correlation

\section{Coefficient Correlations ${ }^{\text {a }}$}

\begin{tabular}{|lll|r|r|}
\hline \multicolumn{2}{|l|}{ Model } & & \multicolumn{1}{c|}{ Bankable } & \multicolumn{1}{c|}{ Jaminan } \\
\hline 1 & Correlations & Bankable & 1.000 & -.061 \\
& & jaminan & -.061 & 1.000 \\
\cline { 3 - 5 } & \multirow{2}{*}{ Covariances } & Bankable & .001 & $-7.539 \mathrm{E}-5$ \\
& & jaminan & $-7.539 \mathrm{E}-5$ & .001 \\
\hline
\end{tabular}

a. Dependent Variable: growth

Hasil Statistik Uji Multikolenieritas yang tampak dalam tabel tersebut mengindikasikan tidak terjadi multikolonieritas yang serius. Hal ini juga ditegaskan kembali dari hasil korelasi antar variabel independen tidak ada korelasi cukup serius, disebabkan karena korelasi tertinggi hanya sebesar- 0,061 yaitu antara Ln variabel Jaminan dan Ln variabel Bankable. 
PRIMANOMICS : JURNAL EKONOMI DAN BISNIS - VOL. 17. No. 3 (2019)

Versi Online Tersedia di : https://jurnal.ubd.ac.id/index.php/ds

| 1412-632X (Cetak) | 2614-6789 (Online) |

\section{Uji Heteroskedastisitas}

Gambar 4.6 Uji Grafik Scatterplot

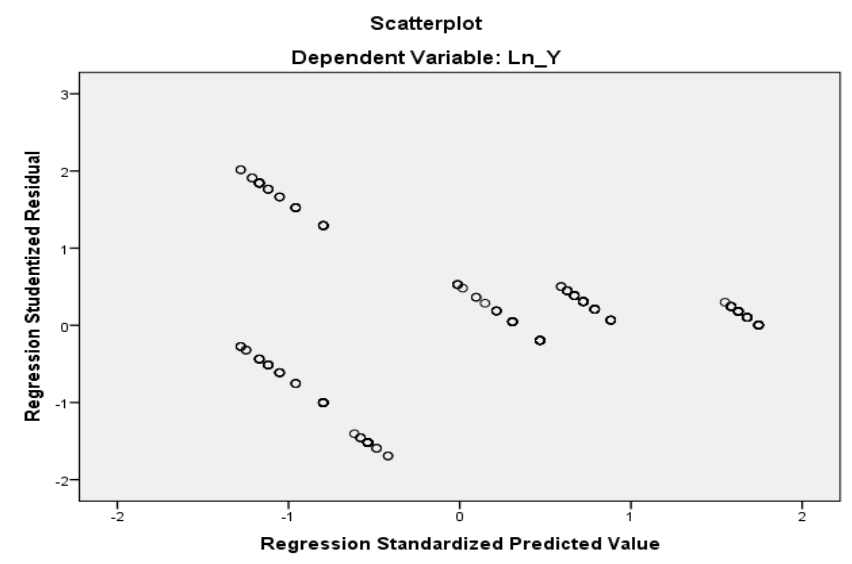

Hal ini mengindikasikan bahwa tidak terjadi heteroskedastisitas pada model regresi, sehingga model regresi layak dipakai untuk memprediksi variabel Penjaminan Kredit Daerah, dan Bankable UKM terhadap Pertumbuhan UMKM dalam regresi, Baik secara parsial ataupun simultan.

\section{Uji Autokorelasi}

Tabel 4.10 Hasil Uji Model Besarnya R Square dalam Koefisien Determinasi

\begin{tabular}{|l|r|r|r|r|r|}
\hline & & & & & \\
Model & $\mathrm{R}$ & $\mathrm{R}$ Square & $\begin{array}{c}\text { Adjusted R } \\
\text { Square }\end{array}$ & $\begin{array}{c}\text { Std. Error of } \\
\text { the Estimate }\end{array}$ & $\begin{array}{c}\text { Durbin- } \\
\text { Watson }\end{array}$ \\
\hline 1 & $.244^{\mathrm{a}}$ & .060 & .054 & .43384 & .158 \\
\hline
\end{tabular}

a. Predictors: (Constant), layak1, jaminan1

b. Dependent Variable: tumbuh1

Sumber data : PT Jamkrida Banten 2019, diolah.

Sedangkan hasil uji standar error of estimate (SEE) sebesar 0.43384. Hal ini menandakan bahwa semakin kecil nilai Standard Error of Estimate (SEE) akan membuat model regresi semakin tepat dalam memprediksi variabel dependen.

Uji F

Tabel 4.11 Hasil Uji Anova Signifikansi Simultan (Uji Statistik F)

ANOVA $^{a}$

\begin{tabular}{|ll|r|r|r|r|c|}
\hline \multicolumn{2}{|l|}{ Model } & \multicolumn{1}{|c|}{$\begin{array}{c}\text { Sum of } \\
\text { Squares }\end{array}$} & \multicolumn{1}{c|}{ df } & $\begin{array}{c}\text { Mean } \\
\text { Square }\end{array}$ & F & Sig. \\
\hline 1 & Regression & 3.781 & 2 & 1.890 & 10.043 & $.000^{\mathrm{b}}$ \\
& Residual & 59.666 & 317 & .188 & & \\
& Total & 63.447 & 319 & & & \\
\hline
\end{tabular}

a. Dependent Variable: tumbuh1

b. Predictors: (Constant), layak1, jaminan1

Sumber data : PT Jamkrida Banten 2019, diolah 
Hasil Output SPSS versi 22 Statistik uji ANOVA atau F test didapat nilai F hitung sebesar 10.043 dengan probabilitas signifikannya sebesar 0,000 sedangkan nilai $\mathrm{F}$ tabelnya sebesar 3,021174. Hasil ini menunjukkan bahwa $10.043>3,021174$ (Fhitung $>$ F tabel) juga nilai probabilitas 0,000 lebih kecil dari 0,05, maka model regresi dapat digunakan untuk memprediksi pengaruh secara bersama sama (simultan) antara variabel Penjaminan Kredit Daerah dan Bankable UMKMM terhadap Pertumbuhan UMKMM. Dengan kata lain bahwa; Fhitung $\geq$ Ftabel, maka Ho ditolak dan Ha diterima artinya ada pengaruh secara bersama sama (simultan) variable independen terhadap variabel dependen.

\section{Uji T}

Tabel 4.12 Hasil Uji Signifikansi Parsial (Uji Statistik T) Coefficients $^{\mathrm{a}}$

\begin{tabular}{|c|c|c|c|c|c|}
\hline \multirow[b]{2}{*}{ Model } & \multicolumn{2}{|c|}{$\begin{array}{l}\text { Unstandardized } \\
\text { Coefficients }\end{array}$} & \multirow{2}{*}{$\begin{array}{c}\text { Standardized } \\
\text { Coefficients } \\
\text { Beta }\end{array}$} & \multirow[b]{2}{*}{$\mathrm{t}$} & \multirow[b]{2}{*}{ Sig. } \\
\hline & $\mathrm{B}$ & Std. Error & & & \\
\hline (Constant) & .114 & .153 & & .746 & .456 \\
\hline jaminan1 & -.072 & .035 & -.111 & -2.028 & .043 \\
\hline layak1 & .182 & .043 & .230 & 4.190 & .000 \\
\hline
\end{tabular}

Sumber data : PT Jamkrida Banten 2019, diolah.

Sementara itu hasil unstandardized beta coefficients hasil output SPSS versi 22 tentang pengaruh antara variabel Bankable UMKMM terhadap Pertumbuhan UMKMM dapat kita amati dengan seksama dimana variabel Bankable UMKMM menghasilkan nilai Thitung sebesar 4,190, sedangkan nilai Sig sebesar 0,000, dengan nilai unstandardized coefficients $(\beta)$ sebesar 0,182 .

Hasil uji variabel Bankable UMKMM dengan hasil Thitug sebesar 4,190, jika kita bandingkan dengan Ttabel dengan $\mathrm{df}=\mathrm{n}-\mathrm{k}-2$ taraf signifikansi 0,05 atau 5\% sebesar 1,649584, maka disimpulkan bahwa; Thitug > Ttabel $(4,190>1,649584)$ dengan nilai signifikansi sebesar 0,000. Artinya Thitung $\geq$ Ttabel, maka Ho ditolak dan Ha diterima artinya ada pengaruh antara variabel Penjaminan Kredit Daerah Terhadap Pertumbuhan UMKM, pengaruhnya arah positif.

\section{KESIMPULAN DAN SARAN}

Kesimpulan dari hasil penelitian ini adalah sebagai berikut :

Variabel Penjaminan Kredit Daerah berpengaruh secara signifikan terhadap Pertumbuhan UMKM pada perusahaan perusahaan/pelaku UMKM di Provinsi Banten periode pengamatan tahun 2015-2018.

Kesimpulan tersebut setelah mengetahui dari hasil penelitian dimana; Thitug $>$ Ttabel $(2,028>1,649584)$ dengan nilai signifikansi sebesar 0,043 . Artinya Thitung $\geq$ Ttabel , maka Ho ditolak dan Ha diterima artinya ada pengaruh antara variabel Penjaminan Kredit Daerah Terhadap Pertumbuhan UMKM, namun pengaruhnya menunjukkan kearah negatif. 
PRIMANOMICS : JURNAL EKONOMI DAN BISNIS - VOL. 17. NO. 3 (2019)

Versi Online Tersedia di : https://jurnal.ubd.ac.id/index.php/ds

| 1412-632X (Cetak) | 2614-6789 (Online) |

Artinya bahwa; Semakin banyak perusahaan / pelaku UMKM yang hutangnya dijaminkan oleh lembaga penjamin hutang (PT Jamkrida Banten), maka akan meningkatkan pertumbuhan UMKM, sehingga semakin besar pula kesempatan untuk meningkatkan pertumbuhan ekonomi.

Variabel Bankable UMKM berpengaruh Positif secara signifikan terhadap Pertumbuhan UMKM pada perusahaan perusahaan/ pelaku UMKM di Provinsi Banten periode pengamatan tahun 2015-2018.

Kesimpulan tersebut setelah mengetahui dari hasil penelitian dimana; Hasil uji variabel Bankable UMKM dengan hasil Thitug sebesar 4,190, dengan df $=\mathrm{n}-\mathrm{k}-2$ taraf signifikansi 0,05 atau 5\% sebesar 1,649584, maka; Thitug > Ttabel $(4,190>1,649584)$ dengan nilai signifikansi sebesar 0,000 . Artinya Thitung $\geq$ Ttabel, maka Ho ditolak dan Ha diterima artinya ada pengaruh antara variabel Bankable UMKM Terhadap Pertumbuhan UMKM, pengaruhnya menunjukan arah positif.

Artinya bahwa; Semakin banyak perusahaan/pelaku UMKM yang layak untuk berhutang kepada perbankan, maka Tidak akan meningkatkan pertumbuhan UMKM, asumsinya diharapkan akan semakin Kecil kesempatan untuk mendapatkan laba sehingga akan Menurunkan pertumbuhan ekonomi.

Variabel Penjaminan Kredit Daerah dan Bankable UMKM berpengaruh positif signifikan terhadap Pertumbuhan UMKM pada perusahaan perusahaan/pelaku UMKM di Provinsi Banten periode pengamatan tahun 2015-2018.

Kesimpulan tersebut setelah mengetahui dari hasil penelitian dimana; Variabel Penjaminan Kredit Daerah dan Variabel Bankable UMKM menghasilkan nilai Fhitung sebesar 10,043, sedangkan nilai Sig sebesar 0,000. dengan $\mathrm{df}=\mathrm{n}-\mathrm{k}-2$ taraf signifikansi 0,05 atau 5\% sebesar 3,021174, maka dapat disimpulkan bahwa; Fhitug > Ftabel $(10,043>3,021174)$ dengan nilai signifikansi sebesar 0,000. Artinya Fhitung $\geq$ Ftabel, maka Ho ditolak dan Ha diterima artinya ada pengaruh antara variabel Penjaminan Kredit Daerah dan Bankable UMKM secara simultan Terhadap Pertumbuhan UMKM, pengaruhnya menunjukan arah positif.

Hasil penelitian ini menunjukan bahwa: Banyaknya perusahaan/ pelaku UMKM yang mendapatkan akses ke perbankan (hutang) kemudian dijamin oleh lembaga penjamin hutang (PT Jamkrida Banten) akan meningkatkan pertumbuhan UMKM, dan diharapkan akan meningkatkan pertumbuhan ekonomi.

\section{Saran}

Berdasarkan kesimpulan di atas, maka penulis dapat memberikan saran-saran sebagai berikut:

Saran bagi Manajemen Perusahaan

Bagi perusahaan perbankan sebagai penyalur kredit jangan takut untuk memberikan hutangnya kepada perusahaan/ pelaku UMKM selama perusahaan/ pelaku UMKM tersebut memenuhi kriteria kelayakan yang dimaksud. Dengan demikian akan meningkatkan pertumbuhan penjualan perusahaan perbankan tersebut 
sehingga akan meningkatkan laba perusahaan. Saran komposisi total piutangnya tidak melebihi modal sendirinya yang besar dan efisien dalam penggunaan biaya biaya.

Berdasarkan hasil penelitian tersebut bahwa variabel Penjaminan Kredit Daerah berpengaruh signifikan terhadap variabel Pertumbuhan UMKM, disarankan bagi perusahaan untuk selalu menjaga komposisi stabilitas piutang dan penjualan agar terus berlanjut dengan diiringi dengan kapasitas peningkatan modal sendirinya.

Berdasarkan hasil pengujian yang diperoleh dalam penelitian ini menunjukkan bahwa variabel Bankable UMKM berpengaruh signifikan terhadap Pertumbuhan UKMK. Dengan demikian perusahaan hendaknya dapat mengelola seluruh piutangnya dalam rangka menjaga likuiditas dan kemampuan penyediaan modal sendirinya. Karena tingkat hutang yang tinggi juga akan menyebabkan tingkat keuntungan yang diterima kurang maksimal karena beban hutang. Dengan demikian diharapkan hasil keuntungan dapat dinikmati oleh seluruh perusahaan dan seluruh investor.

\section{DAFTAR PUSTAKA}

Amir Abadi Jusuf. 2000. Akuntansi Keuangan Lanjutan di Indonesia. Peerbit: Salemba Empat. Jakarta

Anggraini, Dewi dan Nasution, Syahrir Hakim. 2013.Peranan Kredit Usaha Rakyat (KUR) Bagi Pengembangan UMKM Di Kota Medan (Studi Kasus Bank BRI. Jurnal Ekonomi dan Keuangan. Vol.1.No(3).Hal:105-116. Medan.

Badan Pusat Statistik Indonesia dalam angka, 2016. (https://www.bps.go.id/linkTabelStatis/view/id/1322 ) (diakses 3/1/2017).

Bank Indonesia Banten, 2017. Situs Resmi https://www.bi.go.id/statistik, Kajian ekonomi dan keuangan regional Banten, Serang.

Berry, A., Rodriquez, E., \& Sandeem, H. 2001. Small and Medium Enterprises Dynamics in Indonesia. Bulletin of Indonesian Economic Studies, Vol.37, No. 3. Australian National University. Canberra. Australia.

Chariri, A. 2008. Kritik Sosial Atas Pemakaian Teori Dalam Penelitian Pengungkapan Sosial dan Lingkungan. Jurnal Maksi, 8, 151-169.

Carree, M. A., \& Thurik, A. R. (2003). The Impact of Entrepreneurship on Economic Growth. International Handbook of Entrepreneurship Research, 437-71. http://doi.org/10.1007/978-1-4419-1191-9_20

Darwanto. 2013.Peningkatan Daya Saing UMKM Berbasis Inovasi Dan Kreativitas (Strategi Penguatan Property Right Terhadap Inovasi Dan Kreativitas).Jurnal Bisnis dan Ekonomi.(JBE).Vol.20.No(2).Hal:142-149. http://www.depkop.go.id (diakses 22/1/2017).

Deegan, C., Rankin, M. and Tobin, J. (2002), “An examination of the corporate social and environmental disclosures of BHP from 1983-1997", Accounting, Auditing \& Accountability, Vol. 15 No. 3, pp. 312-43..

Devi Wulandari. 2009. Pengaruh Pemberian Kredit Mikro Utama Terhadap Kredit Bermasalah dan Dampaknya Terhadap Laba Operasional. Universitas Siliwangi Tasikmalaya: Tidak diterbitkan. 
PRIMANOMICS : JURNAL EKONOMI DAN BISNIS - VOL. 17. NO. 3 (2019)

Versi Online Tersedia di : https://jurnal.ubd.ac.id/index.php/ds

| 1412-632X (Cetak) | 2614-6789 (Online) |

Dinas Koperasi dan UMKM Provinsi Banten, 2014. Situs Resmi https:// dinkopukm.bantenprov.go.id Data Center.

Donaldson, T., and L. E. Preston (1995). The Stakeholder Theory of the Corporation: Concepts, Evidence, and Implications. The Academy of Management Review, 20 (1).

Erwin T \& Rogahang. 2013. Pengaruh Modal Sosial terhadap Perilaku Kewirausahaan Suatu Studi pada Pelaku UMKM pada Kecamatan kebaruan Kabupaten Kepulauan Talaud. 1(2).

Freeman, R. E. 1984. Strategic Management: A Stakeholder Approach, Boston, Pitman. USA.

Garbo, A. 2013. Pengaruh Metode Persediaan dan Profit Margin terhadap Market Value pada Perusahaan Manufaktur yang Masuk dalam Daftar Efek Syariah (DES) Periode 2008-2011.

Guthrie, J. and Parker, L.D. (1989), "Corporate social responsibility: a rebuttal of legitimacy theory", Accounting and Business Research, Vol. 19 No. 76, pp. 34352.

Hitt, Ireland, 2007. Strategic Management Competitiveness And Globalization Thomson Higher Education 5191 Natorp Boulevard Mason, OH 45040. Library of Congress Control Number: 2005911294, USA.

Huda, A. N. (2012). The Development of Islamic Financing Scheme for SMEs in a Developing Country : The Indonesian Case. Procedia - Social and Behavioral Sciences, 52, 179-186. http:// doi.org/10.1016/j.sbspro.2012.09.454

Iin Indarti, Sugiartiana. 2012. Pengaruh Pertumbuhan Ekonomi, Pendapatan Asli Daerah, Dana Alokasi Umum terhadap Pengalokasian Anggaran Belanja Modal di Kota Semarang Periode tahun 2005-2009. Fokus Ekonomi , 7 No 2, 1-15.

Iman Pirman Hidayat dan Adi Ridwan Fadillah, 2012. Pengaruh Penyaluran Kredit Usaha Mikro Kecil Menengah (UMKM) dan Pendapatan Operasional terhadap Laba operasional, http://imanph.files.wordpress.com.

Jusmarni , 2016. Pengaruh Sustainability Reporting Terhadap Kinerja Keuangan dari sisi Market Value Ratios dan Asset Management Ratio, Jurnal SOROT Volume 11, Nomor 1, April 2016: $29 \quad-\quad 45 \quad 29$ ISSN 1907-364X http://ejournal.unri.ac.id/index.php/JS, Universitas Riau, Riau.

Kara, M. 2013. Kontribusi Pembiayaan Perbankan Syariah Terhadap Pengembangan Usaha Mikro, Kecil, dan Menengah. Jurnal Ilmu Syariah, XIII(2). Kasmir, 2003. Manajemen Perbankan, Penerbit: PT. Raja Grafindo Persada, cetakan ke-2, Jakarta.

Kasmir, 2004. "Pemasaran Bank”, Penerbit: Kencana, cetakan ke-4, Jakarta.

-------, 2005, Bank dan Lembaga Keuangan Lainnya, Penerbit PT Rajagrafindo Persada, Jakarta.

Laplume et al., 2008. Stakeholder Theory: Reviewing a Theory That Moves Us. Online situs:https:/ / www.reseachgate.net/../236577998 Stakeholders Theory. 
Lukman Dendawijaya. 2005. Manajemen Perbankan, Penerbit: Ghalia Edisi Kedua. Bogor: Indonesia.

Nofianti, H. (2013). Dampak Pembiayaan UMKM oleh Bank Perkreditan Rakyat di Bali terhadap Kinerja Bank. E-Jurnal Ekonomi Dan Bisnis Universitas Udayana, 2(2), 1-16. Bali.

Nurdianita, Afritasari; Hascaryani, T. D. (2015). Komparasi Efisiensi Bank pada Pembiayaan UMKM Sebelum dan Sesudah Adanya Peraturan Bank Indonesia Nomor14/22/PBI/2012. Jurnal Ilmiah Mahasiswa FEB Universitas Brawijaya, 3(2). Mankiw, N. Gregory. 2003. Makro Ekonomi; Erlangga, Jakarta.

Peraturan Pemerintah Nomor. 41 Tahun 2008. Tentang Perusahaan Umum Perum Jaminan Kredit Indonesia, Jakarta.

Peraturan Pemerintah Nomor 51 Tahun 1981 tentang Pendirian Perusahaan Umum Pengembangan Keuangan Koperasi yang diatur kembali dengan Peraturan Pemerintah Nomor 27 Tahun 1985 tentang Perusahaan Umum Pengembangan Keuangan Koperasi, terakhir dengan Peraturan Pemerintah Nomor 95 Tahun 2000 tentang Perusahaan Umum Sarana Pengembangan Usaha, Jakarta.

Peraturan Menteri Keuangan Nomor 135/PMK.05/2008. Tentang Fasilitas Penjaminan Kredit Usaha Rakyat, Jakarta.

Peraturan Menteri Keuangan Nomor 222/ PMK.010/2008. Tentang Perusahaan Penjaminan Kredit dan Perusahaan Penjaminan Ulang Kredit

Peraturan Daerah Nomor 3 tahun 2013. Tentang Pembentukan Perseroan Terbatas Penjaminan Kredit Daerah Banten, Serang.

Porter, Michael E., 1994. Keunggulan Bersaing, Bina Rupa Aksara, Jakarta.

Putra, Gede Surya Prtama.,dan Mustika, Made Dwi Setyadhi. 2014. "Efektivitas Program Jamkrida Dan Dampak Terhadap Pendapatan Dan Penyerapan Tenaga Kerja UMKM. E-Jurnal Ekonomi Pembangunan. Vol.3. No(12) Hal:549-557. Universitas Udayana, Bali.

Ramlan, 2005. Sintaksis. Penerbit: Karyono, Yogyakarta.

Ramlan, 2009. Morfologi: suatu tinjauan deskriptif. Penerbit: Karyono, Yogyakarta.

Rizal Calvary. 2009. Ayo ke Bank Dapatkan Kredit UMKM. Jakarta: PT Elex Media Komputindo. Jakarta.

Robinson, Sandra. L., \& Bennett, Rebecca J. 1998. A typology of deviant workplace behaviors: A multidimensional scaling study. Academy of Management Journal, 38(2): 555-572

Saputro.J.W., Handayani, Putu Wuri., Hidayanto, Achmad Nizar.,dan Budi, Indra. 2010. Peta Rencana (ROADMAP) Riset Enterprise Resource Planning (ERP) Dengan Fokus Riset Pada Usaha Kecil Dan Menengah (UMK) Di Indonesia. Journal of Information Systems. Vol.6.No(2).Hal:140-145.

Sholhuddin, Muhammad. 2013. Tantangan Perbankan Syariah Dalam Perannya Mengembangkan UMKM. Proceeding Seminar Nasional Dan Call For Paper Sancall. Hal:496-500. Surakarta. 
PRIMANOMICS : JURNAL EKONOMI DAN BISNIS - VOL. 17. NO. 3 (2019)

Versi Online Tersedia di : https://jurnal.ubd.ac.id/index.php/ds

| 1412-632X (Cetak) | 2614-6789 (Online) |

Sudaryanto; Ragimun; Wijayanti, R. R. (2013). Strategi Pemberdayaan UMKM Menghadapi Pasar Bebas Asean. Pusat Kebijakan Ekonomi Makro. Badan Kebijakan Fiskal. Kementerian Keuangan, Jakarta.

Sukirno, Sadono. 2011. Makro Ekonomi Teori Pengantar. Penerbit: PT Raja Grafindo Persada, Jakarta.

Sugiono, Arief. (2009). Manajemen Keuangan. Penerbit: Grasinda, Jakarta.

Sugianto, 2010. "Peran Penjaminan Kredit Terhadap Usaha Mikro, Kecil, Menengah dan Koperasi pada perusahaan umum Jaminan Kredit Indonesia (Perum Jamkrindo)" Fakultas Syariah dan Ilmu Hukum UIN Negeri Sultan Syarif Kasim, Pekan Baru,

Soemarso S.R. 2002. Akuntansi Suatu Pengantar, Buku 1 Edisi Keempat. Penerbit: Salemba Empat. Jakarta.

Sri Handayani. 2009. Pengaruh Penyaluran Kredit dan Penyisihan Penghapusan Aktiva Produktif Terhadap Laba Operasional. Skripsi Sarjana Ekonomi, Universitas Siliwangi Tasikmalaya: Tidak diterbitkan.

Supriyanto.2006. Pemberdayaan Usaha Mikro, Kecil, Dan Menengah (UMKM) Sebagai Salah Satu Upaya Penanggulangan Kemiskinan. Jurnal Ekonomi Pendidikan.Vol.3.No(1).Hal:1-16.

Susilo, Y. S, 2010. Peran Perbankan dalam Pembiayaan UMKM di Provinsi DIY. Jurnal Keuangan Dan Perbankan, 14(3), 467-478.

Tambunan, H.T, Tulus. 2009. UMKM di Indonesia: Penerbit: Ghalia, Bogor. Indonesia.

Tambunan, T. T. (2012). Perekonomian Indonesia Kajian Teori dan Analisis Empiris, Penerbit: Ghalia, Bogor Indonesia.

Thomas,Suyatno. 2003. Dasar-Dasar Perkreditan : Penerbit: PT. Gramedia Pustaka Utama, edisi Keempat, Jakarta.

Undang-Undang Republik Indonesia Nomor 20 tahun 2008. Tentang Usaha Mikro, Kecil, dan Menengah, Jakarta, Indonesia.

Undang-Undang Republik Indonesia Nomor 1 Tahun 2016. Tentang Penjaminan, Jakarta, Indonesia.

Undang-Undang Republik Indonesia Nomor 21 Tahun 2011. Tentang Otoritas Jasa Keuangan (OJK), Jakarta Indonesia.

White (1996).Juornal of philosophy akses situs https:// www.onlinelibrary.wiley.com.../j.1467-9752.1996 